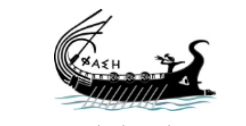

journal.phaselis.org

\title{
Arkaik Kutsal Alanlarda Yer Seçimini Belirleyen Etmenler
}

\author{
Site Selection Factors in Determining the Archaic Sanctuary
}

\author{
Kenan EREN
}

open access journals

PHASELIS: Disiplinlerarası Akdeniz Araştırmaları Dergisi'nde bulunan içeriklerin tümü kullanıcılara açık, serbestçe/ücretsiz "açık erişimli" bir dergidir. Kullanıcılar, yayıncıdan ve yazar(lar)dan izin almaksızın, dergideki makaleleri tam metin olarak okuyabilir, indirebilir, dağıtabilir, makalelerin çıktısını alabilir ve kaynak göstererek makalelere bağlantı verebilir.

PHASELIS: Disiplinlerarası Akdeniz Araştırmaları Dergisi uluslararası hakemli elektronik (online) bir dergi olup değerlendirme süreci biten makaleler derginin web sitesinde (journal.phaselis.org) yıl boyunca ilgili sayının içinde (Volume I: Ocak-Aralık 2015) yayımlanır. Aralık ayı sonunda ilgili yıla ait sayı tamamlanır.

Dergide yayımlanan eserlerin sorumluluğu yazarlarına aittir. 


\title{
Arkaik Kutsal Alanlarda Yer Seçimini Belirleyen Etmenler
}

\author{
Site Selection Factors in Determining the Archaic Sanctuary
}

\author{
Kenan EREN*
}

\begin{abstract}
Öz: Kutsal Alanlar, kendilerini inşa eden toplumun insan ilişkilerini ve doğaüstüne bakışlarını yansıtırlar; yani bir anlamda kişinin etrafındaki dünyayı algılamasının bir yansımasıdırlar. Dolayısıyla kutsal alanların konumları, onları yaratan toplumun etrafındaki dünyaya ilişkin oluşturduğu 'zihinsel haritayla' bağlantıı olarak düşünülebilir. Antikçağda bir coğrafyada belirli bir toprak parçasına nasıl kutsallık yüklendiği sorusunun yanıtı da bu haritayı oluşturan etmenlerin tanımlanması ve anlaşılması sürecini gerektirmektedir. Antik metinlerin incelenmesi, fiziksel coğrafyanın yer seçiminde önemli bir etken olduğunu ve doğadaki dikkat çekici noktalarda sıklıkla kutsal alanların oluştuğunu göstermektedir. Benzer bir şekilde, daha eski dönemlerden itibaren kült aktivitelerine sahne olduğu düşünülen alanlara da özel bir saygı gösterildiği ve buraların kutsal alanlar olarak tanımlandığı da ortaya koyarlar. Ancak arkeolojik araştırmaların sonuçları, antik metinlerin yer seçiminin asıl belirleyicisi gibi gözüken beşeri coğrafyanın kült coğrafyasının şekillenmesindeki etkisine çok az değindiğini de ortaya koymaktadır.
\end{abstract}

Anahtar sözcükler: Kutsal Alan · Konum · Arkaik · Polis · Kült

Abstract: Sanctuaries reflect the relations with the supernatural forces by a society and, in a sense, they are the reflection of the perception of the world around the person. Therefore the location of a sanctuary may be considered as a result of 'the cognitive map', of the society that created it. The answer as to what prompted people to upload sanctity onto a specific piece of land requires the identification and the understanding of the factors that shape this imaginary map. The examination of ancient texts shows the physical geography was always an important factor and attractive natural points were often conducive to the foundation of a sanctuary. Similarly, those places that were considered as "old" cult places were often recognized as sacred places and sanctuaries were placed there. However, as revealed through archaeological research, ancient texts seldom mentioned the importance of the human geography, even though this factor seems to be the major determinant in the location of sanctuaries.

Keywords: Sanctuary · Location · Archaic · Polis · Cult

Hellen kentinin ortaya çıkışı ve kentsel mekânın oluşum süreci antikçağ araştırmaları içerisinde en çok sorgulanan konulardan birini oluşturmaktadır. Bu sorgulamanın önemli alt başlıklarından birisini ise 'polis' kavramının ortaya çıkısıına paralel olarak M.Ö. VIII. yüzyıldan itibaren kutsal alanların sayısında gözlemlenen büyük artışın anlaşııma çabası oluşturur. Görüldüğü kadarıyla M.Ö. VIII. yüzyıl öncesinde hemen hemen hiçbir kutsal alan kent merkezlerinde konumlanmamaktadır ve arkeolojik olarak tespit edilmiş kutsal alanlar toplulukların yaşam alanlarından belirli bir uzaklıkta yer almaktadır ${ }^{1}$. Anlaşılan kentleşmeye doğru gelişim, kült aktivitelerine

* Yrd. Doç. Dr., Mimar Sinan Güzel Sanatlar Üniversitesi, Arkeoloji Bölümü, İstanbul. kenaneren@msgsu.edu.tr

1 Mazarakis 1988, 105. 
ayrılmış bir takım özel mekânların gelişimini de tetiklemiştir. Böylelikle kutsal alanlar kent coğrafyası içerisinde konumu tanımlanmış ilk kamu alanları olarak, ilk kuruluş aşamasından itibaren şekillenmeye başlamışlardır². Bu bağlam içerisinde, yeni şekillenen kutsal alanların konumlarının ön bir incelemesi yapılmakla birlikte, aynı zamanda kendilerini inşa eden toplumların insan ilişkilerine ve doğaüstü güçlere yönelik bakış açılarının da anlaşılmasına katkı sağlayacaktır. Böyle bir araştırmanın en önemli problemlerinden birisini ise "Ne zaman ve neden bir kült aktivitesi hem fiziksel, hem de sosyal olarak daha görünür hale gelir?" sorusu oluşturur ${ }^{3}$. Topluluklar için çok özel bir anlam taşıyan ve bir manada da bir topluluğun tanrılarla olan ilişkilerinin düzenlenmesine katkıda bulunan özel noktaların belirlenmesi, onları yaratan toplumun zihinsel haritasıyla bağlantılı olarak düşünülmelidir.

Hellen tarihi ile ilgili bir çalışma kapsamında değerlendirildikleri zaman kült alanları, en genel anlamlarıyla, tanrılara ayrıımış ve belli sınırları olan kutsal bir toprak parçasını ifade etmektedir. Bu sınırları belirlenmiş alanın Hellence adı "temenos"tur ve bu sözcük "kesmek", "ayırmak" anlamına gelen fiilden türetilmiştir". Kültün nitelikleriyle ve bulunduğu yerdeki insan topluluğu için önemiyle doğru orantılı olarak kutsal alana bazı yapılar eklenmektedir; bu yapıların en önemlileri tanrı veya tanrıçanın evi kabul edilen tapınak ile kült faaliyetlerinin odak noktası olan sunak olarak kabul edilebilir. Bu alanın konumunun nasıl belirleneceği sorununa eğilmeden önce bir noktanın altını çizmek gereklidir. Hellenler için kutsallık kült yapısının kendisinde değil, o yapının yer aldığı toprakta gizlidir; başka bir deyişle bir kült yapısı, konumlandığı alanın kutsallığından dolayı oraya inşa edilir ${ }^{5}$. Zaten Hellence'de "kutsal" sözcüğünün yerine kullanılan, ancak kendi içlerinde anlam farklılıkları olan üç ayrı sözcük (hieron, hosion ve hagion) bulunmaktadır. Bunlardan "hieron" ya da "hiera" kült yapılarını tanımlamak için kullanılır ve kült yapısının bulunduğu toprağın kutsallığını da vurgular ${ }^{6}$. Kült alanının kutsallığının bozulmadan korunması için sınırları "horoi" adı verilen yalın işaretlerle belirtilir ya da daha etkileyici olması amacıyla yanları çitle ya da duvarla (peribolos) çevrilirler?. Yine altı çizilmesi gereken bir başka özellik, kent merkezi ve kırsalın kendine özgü, özellikleri açısından birbirinden kesin çizgilerle ayrışan tanrı ve tanrıçalara sahip olmamasıdır, benzer bir durum kutsal alan mimarisi için de gözlemlenebilir. Kent merkezinde kutsal mağaralar gözlemlenirken, anıtsal tapınaklar da kent kırsalında yer alabilir ${ }^{8}$. Anlaşılan Hellen dininin dogmatik olmayan karakteri kendisini kült alanlarının biçimlenmesinde de göstermiştir.

Kutsal alanların kent arazisi üzerinde nerelere konumlandıklarını sorgulayan pek çok çalışmada, kutsal alanların konumu ile kentlerin gelişimi arasında bir bağ kurulmaya çalışıldığı gözlemlenebilir. M.Ö. 750'lerden itibaren kutsal alanların sayısının kent surları ve nekropol alanlarının belirlenmesine paralel olarak artması, genelde polis'in ortaya çıkısının bir başka göstergesi olarak tanımlanmışı ı. Bu tip çalışmalarda altı çizilen en önemli nokta, sadece dinsel aktivitelere ayrılmış alanların belirlenmesinin, tanrılara ayrılan bölgelerin belirlenmesini de içeren yeni bir tip

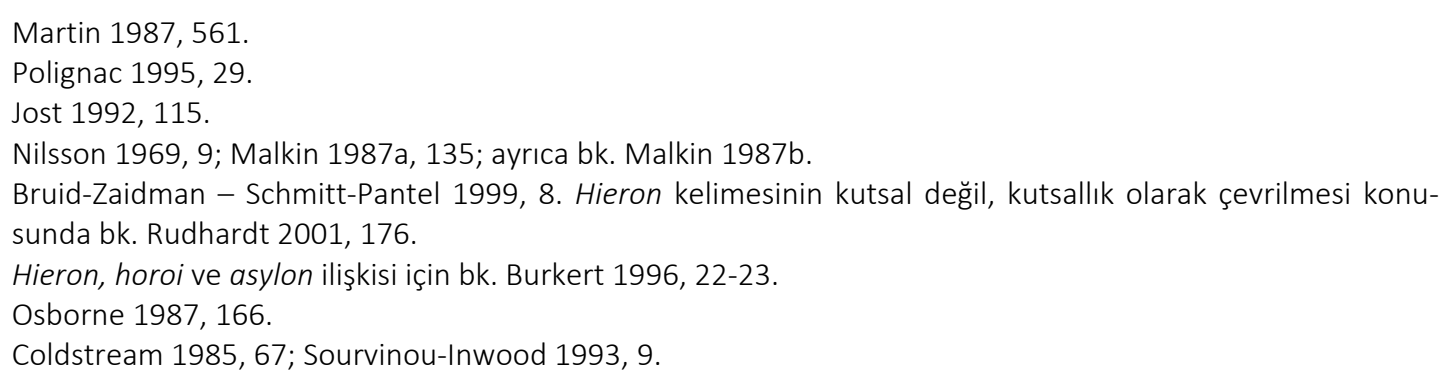


mekân hiyerarşisi anlayışının uzantısı olduğudur ve nekropol alanlarının ya da kamusal alanların belirlenmesi de bu mekânsal bölünmenin diğer aşamalarını oluşturur ${ }^{10}$. Antik kaynaklar, yeni bir kent kurmanın aynı zamanda bir mekânsal düzenleme yapmayı da gerektirdiği konusunda önemli bilgiler aktarırlar. Örneğin Homeros yeni bir kent kuran Nausithoos'un yaptıklarını şöyle anlatır:

\section{"Dört yandan surla çevirmişti kenti, evler kurmuş, tapınaklar yaptırmıştı tanrılara, tekmil toprakları dağıtmıştı"11.}

Görüldüğg̈ gibi surların inşası, konut alanlarının belirlenmesi, arazinin bölüştürülmesi ve tanrılara ayrılan toprakların belirlenmesi yeni kurulan bir kentin en öncelikli işleri gibi görünmektedir ${ }^{12}$. Buna bağ ı olarak da özellikle yeni şekillenen kentlerde, kamusal ve özel alanların en erken dönemlerden itibaren ayrıldığı ve kutsal alanların sınırları kesin olarak tanımlanan ilk kamusal alanlar olduğu kabul edilebilir ${ }^{13}$. Polis'in ortaya çıkışının mekânsal düzenlemeleri nasıl etkilediğinin araştırılması tarihi açısından önemli yapıtlardan birisi F. De Polignac'ın 1984 yılında yayımlanan La Naissance de la Cité Grecque isimli kitabıdır. Polignac bu kitapta kutsal alanların yer seçiminin M.Ö. VIII ve VII. yüzyılların sosyal değişimleri ile ilişkili olarak nasıl şekillendiğini sorgulamaktadır. Yazara göre, sınırları belirli bir araziye sahip kent-devlet fikrinin gelişimi, kent yöneticilerinin sahip oldukları topraklarla ilişkili bir mekân bilinci geliştirmelerine sebep olmuştur ve kutsal alanlar, özellikle kent dışı kutsal alanlar bu bilincin etkisiyle sınır bölgelere, kentin bu bölgelerdeki hâkimiyetinin altını çizecek konumlara yerleştirilirler ${ }^{14}$. Polignac'ın kitabının ardından, kent merkezinin polis'in hâkimiyet sahasının da merkezi olduğu ve buradan yola çıkarak kent toprakları içerisindeki mekânların konumlarının belirlendiğini öngören bir model genel olarak kabul görmeye başlamıştır. Bu modele göre kutsal alanlar kent içi ve kent dışı kutsal alanlar olarak ikiye ayrılmakta ve özellikle kent dışı kutsal alanların konumları, kentin kendi toprakları üzerinde kurduğu otoriter düzen bağlamında değerlendirilmektedir.

Ancak yine de bu tip analizler kent toprakları içerisinde en erken dönemlerden itibaren hiyerarşik bir yapı olduğunu varsaymakta ve kent merkezini de bu hiyerarşik yapının zirvesine yerleştirmektedirler. Ancak söz konusu Geometrik ve Arkaik dönemler olunca, sınırları belirlenmiş bir toprağı mekânsal olarak örgütleyecek bir siyasi iradenin varlığını gözlemlemek pek olası gözükmemektedir $^{15}$. Bu yüzden polis'le ilişkili siyasi ve sosyal gelişmeleri ön plana alan analizleri bir kenara bırakıp, toplulukların kutsal alanlar için yer seçimlerini belirleyen farklı türde etmenlerin izini sürmek bu makalenin ana amacını oluşturmaktadır. Kutsal alanların konumlarını sorgulayacak bir çalışma, üst üste geçmiş pek çok farklı etkeni ve ilişkiler ağını birlikte sorgulayacak topolojik bir araştırmayı zorunlu kılmaktadır. Böyle bir çalışma doğası gereği antik kaynakların ve arkeolojik verilerin karşııklı bir analizini gerektirmektedir ve bu zorunluluk tek bir makale kapsamını çok aşacak bir çalışmayı gerektirir ${ }^{16}$. Dolayısıyla bu çalışma, kutsal alanların yer seçimini

10 Morris 1987, 189.

11 Hom. Od. VI. 7-10.

12 Malkin 1987a, 339.

13 Malkin 1987a, 561.

14 Polignac 1984.

15 F. De Polignac'ın Arkaik kent vizyonuna getirilen bir eleştiri için bk. Malkin 1996, 79-80. Ancak en kapsamlı eleştirileri yapan yine Polignac olacak ve böyle bir örgütlenmeyi organize edecek politik oluşumların Klasik Dönem ile birlikte ortaya çıktığııın altını çizecektir (Polignac 2006, 205).

16 Kutsal alanları pek çok farklı açıdan irdeleyen geniş bir bibliyografya mevcuttur, yakın tarihli bir sentez çalışması için bk. Brulé 2012. 
etkilediği tarafımızca düşünülen birkaç etmene yoğunlaşacak ve etmenlerin kavramsal arka planını anlamak için antik kaynaklara başvurulacaktır.

Klasik Dönem kaynakları bize ideal bir kentin nasıl planlanacağı ve bu plan içerisinde kutsal alanların nerelere konumlanması gerektiği ile ilgili düşüncelerden pasajlar içerirler. Örneğin Platon ideal bir kentin kuruluşunu "Yasalar" isimli eserinde şu şekilde tarif etmektedir:

"Kent için bütün öteki elverişli koşullara sahip olan bir yer seçildikten sonra, kenti ülkenin olabildiğince ortasına kurmaktır... Sonra da, başta Hestia, Zeus ve Athena tapınakları olmak üzere, kutsal yerler belirlenip, buraya 'akropolis' adı verilerek çevresi çevrildikten sonra, buradan hareketle tüm ülkeyi ve kenti on iki parçaya bölmelidir"'17.

Görüldüğü gibi bir kent kurulurken ilk yapılması gerekenlerden birisi, kutsal alanların belirlenmesi ve tapınakların inşa edilmesi olmalıdır. Kent içinde yer alan tapınaklar doğal olarak kent merkezinin gelişmesiyle yakından ilintilidirler. Arkaik Dönem'de tapınak kurmak için genelde akropolis'in tercih edildiği görülebilir. Şehrin en yüksek noktasında uzaklardan görülebilecek bir kutsal alan içinde, kentin kendi tanrısına anıtsal bir tapınak kurulması, bir bakıma polis'in kurulmasının geriye dönük bir kanıtı olarak düşünülebiliir ${ }^{18}$. Antik kaynakların da, kent içi kutsal alanların konumlarından bahsederken, bu alanın kentin her yerinden görünebilir olmasına özel bir önem verdikleri görülmektedir. Ayrıca kutsal alanın saflığının korunması açısından da temenos'un yüksekte bir noktada yer alması fikri antik düşünürlerce desteklenmiştir:

"Tapınak ve altarlar için en uygun olan alan; en göz önünde olan, ancak halkın ulaşmasının zor olduğu yerdir; bu sayede dua eden insanlar hem orayı görmekten keyif duyarlar, hem de oraya yaklaşmak safık duygusu verir"119.

"Tapınakları çarşı alanıyla tüm kentin çevresinde, güvenlik ve temizlik amacıyla yüksek alanlara çepeçevre kurmak gerekiyor"20.

"Halka ait tapınma mekânları şehirle uyumlu olmalıdır; ancak bunun istisnası kanunun veya Delphoi kehanet ocağının uzakta ve ayrı durmalarını söylemesidir. Kutsal alan, şehrin mahallerini kumanda edebilmesi için yüksekte yer almalıdır"21.

Klasik Dönem yazılı kaynakları, kent merkezinde yer alan kutsal alanlar için en tercih edilen yerin akropolis olduğunun altını çizmektedir. Bu konum aynı zamanda, kent vatandaşlarında tanrı tarafından gözlemlendikleri ve korundukları hissini güçlendirmekte ve kutsal olanın dünyevi hayattan ayrımını somutlaştırmaktadır. Ancak arkeolojik araştırmalar kent merkezinde yer alan kutsal alanların pek çok farklı noktada konumlanabileceklerini de bize göstermiştir. Özellikle deniz kıyısında yer alan kentlerde, liman yakınında bir kutsal alanın varlı̆̆ı yaygın olarak görünmektedir. Bu makalenin konusu dışında olsa da, limanlarda yer alan kutsal alanların, prestij simgeleriyle süslü, daha çok topluluğun ileri gelenlerine ait sunu objelerinin görüldüğü akropolis tapınaklarının aksine, daha çok kadınlara ve denizcilere açık alanlar oldukları düşünmek mümkün

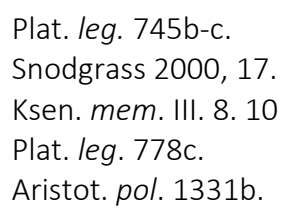


görülmektedir ${ }^{22}$.

Kent kırsalında yer alan kutsal alanların konumları incelenirken, kent merkezi ile kurulan ilişki üzerinden oluşmuş geleneksel sınıflandırma biçimine alternatifler arandığında kutsal alanların konumlarını değerlendirme süreci daha karmaşık bir hale bürünmektedir. Bu bağlamda, topografyanın veya daha bütüncül olarak fiziki coğrafyanın kutsal alanların yer seçimine etkisi araştırma tarihinde özellikle üzerinde durulmuş alanlardan biridir. Anlaşılan mağara, su kaynağı, belirgin bir kayalık ya da anıt ağaç gibi dikkat çekici noktalar doğaüstü güçlerle temasa geçmek için daha uygun noktalar gibi görünmüştür ${ }^{23}$. Kutsal alanlar her şeyden önce insanüstü güçlerle iletişime geçilmesini sağlayan yerlerdir ve mekâna özgün bazı özellikler bu iletişimi daha verimli kılabilirler ${ }^{24}$. Antik kaynaklar doğayla uyum hissi veren veya bazı tanrı/tanrıçalarla ilişkili işaretler olarak yorumlanabilecek özelliklere sahip yerlerin de kutsal alan olarak tanımlanmaya daha elverişli olduğunu göstermektedir. Burada hemen Phaedra ile Sokrates'in Ilissos kenarında yaptıkları gezinti akla gelmektedir. Görkemli ağaçlar ve güzel kokulu çiçeklerle dolu bir su kaynağı onları görür görmez etkiler ve burasının nymphe'ler ile Akhelaous'a adanmış bir kutsal alan olduğuna karar verirler ${ }^{25}$.

Bir başka örnek ise Sophokles'in Oidipus Kolonos'ta tragedyasının açılış sahnesinde görülebilir. Burada yorgun Oedipus oturup dinlenecek bir yer aramaktadır ve kızı Antigone defne ağaçları, zeytinler ve üzümlerle dolu, içerisinde bülbüllerin şakıdığı bir yerde durup dinlenmelerini teklif eder, çünkü burası şüphesiz kutsal bir alan olmalıdır:

“... Bulunduğumuz yer eminim ki mukaddes bir yer, çünkü her tarafta defneler, zeytin ağaçları, üzüm kütükleri var; içeride yapraklar altında da binlerce bülbül şakıyor. Şuraya şu sert taşın üzerine otur da vücudun bir dinlensin ...."26.

Anlaşılan yerin ruhu ve bunu simgeleyen coğrafyadaki farklılıklar, oranın kutsal olarak tanımlanmasına yol açabilmektedir ${ }^{27}$. Coğrafya bazı özel deneyimlerin yaşanmasını sağlaması açısından önemli bir etmendir. Yine de kutsal alan konumlarının ayrıntılı bir incelemesi, böylesine baskın bir coğrafi determinizmin varlığının kuşkulu olduğunu ortaya koymaktadır. Şüphesiz ki coğrafya bazı stratejileri etkilemiştir. Ancak bireylerin etraflarını çevreleyen doğayla ilişkileri çok daha karmaşıktır ve tek başına baskın bir ögeyi tanımlamak mümkün değildir. Yine de antropolog Clifford Geertz'in söylediği gibi, fiziksel çevre sosyal ve ekonomik faaliyetleri derinden etkilediği için dinsel aktivitelerle ilgili analizlerden hiçbir zaman dışlanmamalıdır ${ }^{28}$.

Kutsal alanlar elbette her şeyden önce insanlar tarafından konumları ve sınırları belirlenen alanlardır ve fiziksel coğrafyanın ötesinde beşeri coğrafyanın yer seçiminde en belirgin etmen olduğunu gözlemlemek mümkün görünmektedir. Kült aktivitelerinin takvimi incelendiğinde, özellikle tarımın ve tarım arazilerinin kültün doğasının ve coğrafyasının şekillenmesinde büyük bir yer tuttuğu anlaşılmaktadır ${ }^{29}$. Bireylerin etraflarındaki dünyayla kurdukları ilişkinin doğası in-

22 Bu karşıtlığın iyi incelenmiş bir örneği için bk. Simon 1997.

Scully 1963, 3, 44.

Brulé 2012, 29-30.

Plat. Phaidr. 230b.

Soph. Oid. K. IX-XX.

Bruid-Zaidmann - Schmitt-Pantel 1999, 55.

Geertz 1993, 143.

9 Osborne 1987, 165. 
celendiğinde, farklı dönemlerde bile olsa çevrelerindeki doğayla kurdukları ilişkilerin büyük değişiklikler geçirmediği ve buna bağıı olarak dinsel coğrafyanın kendisini sıklıkla tekrar ettiği de görülebilir ${ }^{30}$. Bu kalıcılı̆ıın ve döngüselliğin dinsel alana bir tezahürü, mevcut dinsel alanlara saygı gösterilmesi ve farklı kültürel kontekstlerin, geçmişten kalan kutsallığı devralma alışkanlığıdır.

Yeni gidilen topraklarda bulunan kutsal alanlar bu noktada önem kazanır. Geleneğin tanımladığı kutsallık daima önemlidir ve saygı gösterilmesi gereklidir. Platon bu noktanın altını özellikle çizer;

"Her bir köyde de öncelikle tanrıların ve onları izleyen daimonların tapınaklarıly pazar alanı seçilmeli; bunlar ister Magnesialıların yerli tanrıları, ister anılarda hala canlı başka eski tanrıların tapınakları olsun, eski insanların bu tanrılara gösterdiği saygı sürdürülmeli’’31.

Eski kutsal alanlar her zaman benimsenmiştir ve bir yer bir kere kutsal sayıldı mı, bu kutsallığı hep devam eder. Bu konuda birkaç örnek daha verilebilir. Örneğin Brea'da bir koloni kurulması ile ilişkili olarak keşfedilmiş bir Atina dekretine göre:

"Daha önceden kalan kutsal alanlar korunmalı ve oraya yenileri yerleştirilmemelidir" 32 .

Thukydides'de de mevcut kutsal alanlara saygı gösterilmesinin bir zorunluluk olduğu görülmektedir:

"Atinalılar bu konuşmaya kutsal yerlere hiçbir saygısızlık yapmadıklarını ve yapmayacaklarını söyleyerek karşılık verdiler... Boiotialılar ve başka Hellenler de kovdukları insanların tapınaklarını kendi tapınakları gibi görürlerdi"33.

Antik kaynaklara göz atılması, antikçağda kutsal alanların konumlarının nasıl seçildiği ile ilgili bize bir takım ipuçları sağlamaktadır. Görüldüğü gibi kült alanının görünürlüğü, doğada ilgi çeken noktaların sağladığı kutsallık, ya da geleneğin kutsallık atfettiği alanlara gösterilen saygı en çok altı çizilen yer seçimi faktörleridir. Antik metinler fiziksel coğrafyanın ve tarihsel coğrafyanın (bazı durumlarda bu "hayali" bir yaklaşım olsa bile) kutsal alan seçimlerine olan etkisini ortaya koymaktadır $^{34}$. Ancak arkeolojik araştırmalar fiziksel ve tarihi coğrafyanın belirleyici etkisinin aslında bilinen kutsal alanların küçük bir bölümü için geçerli olduğunu ortaya koymuştur. Buna karşılık pek çok kutsal alan özellikle tarımsal ve ekonomik aktivitelerle ilişkili olarak konumlandırılmış gibi görünmektedir. Geleneksel sınırlarla çevrili, ailelere dağııılmış ve tarıma açılmış topraklar ve onların çevresinde gelişen beşeri coğrafya, anlaşılan kutsal alanların seçiminde en belirleyici etmen olmuştur.

Bu makalenin konusunu oluşturmasa da, muhtemelen yer seçimine önemli etkisi olan faktörlerden birisi, yollarla ve limanlarla kurulan ilişkidir. Önemli kara ve deniz yolları üzerinde, özellikle kavşak işlevi gören ve pek çok farklı bölgeden gelen yolların birleştiği noktalarda büyük ve önemli kutsal alanların geliştiği uzun zamandır bilinmektedir. Arkaik Dönem'de, yollarla,

30 Horden - Purcell 2000, 406.

31 Plat. leg. 704b-705c.

32 ML 49, 9-11.

33 Thuk. IV. 98.

34 Hellas'ta coğrafya algısı üzerine bk. Guettel-Cole 2004, 7-8. 
özellikle deniz yollarıyla kurulan ilişkinin bu anlamda çok daha önemli olduğu da anlaşılmaktadır. Bu doğrultuda denizle bağlantılı aktivitelerin Arkaik Dönem'de Akdeniz hayatının tam merkezinde yer aldığı anlaşıımaktadır ve anlaşılan Ege Dünyası'nda buna paralel olarak bir kült topografisi zaman içinde oluşmuştur ${ }^{35}$. Bu makalede özellikle üzerinde durulan nokta ise, Hellen mitolojisi incelenirken dinsel ve din dışı olgular arasındaki belirsizliğin ve dinin dogmatik olmaktan uzak yapısının kült alanlarının konumlandırılmasına nasıl etki ettiğinin gösterilmesidir. Bölgeden bölgeye farklııkların belirginleştiği, ritüellere dayalı bir doğaya sahip olan ve buna bağlı olarak yer seçiminde değişken kriterlerin uygulandığı birçok kutsal alan mevcuttur. Bu bağlam içerisinde, coğrafi determinizm, polis'in teritoryum algısı, kült devamlılığı vs. gibi tekil perspektifler, tek başına bütüncül bir genelleme yapma imkanını vermemektedir. Üst üste geçen pek çok anlamın bulunması, meselenin aslında çok katmanlı olduğunu ve detaylı analizlerin arkeolojik, epigrafik ve filolojik belgelerin bir araya getirilmesi ile mümkün olabileceğini bize göstermektedir.

35 Ionia'nın Akdeniz Dünyası ile geliştirdiği ilişkiler için bk. Eren 2015. 


\section{BIBLIYOGRAFYA}

\section{Antik Kaynaklar}

Aristot. pol.

(= Aristoteles, Politika)

Kullanılan Metin ve Çeviri: Aristoteles, Politica. Trans.: H. Rackham, vol.

Hom. Od. XXI. Cambridge, Massachusetts - London $2005^{10}$ (The Loeb Classical Library). (= Homeros, Odysseia)

Kullanılan Metin ve Çeviri: Homeros, Odysseia. Çev.: A. Erhat - A. Kadir. İstanbul $1988^{6}$.

Ksen. mem.

(= Ksenophon, Apomnemoneumaton)

Kullanılan Metin ve Çeviri: Ksenophon, Memorabilia. Oeconomicus. Symposium. Apology. Trans.: E. C. Marchant - O. J. Todd, vol. IV. Cambridge, Massachusetts - London 2013.

Soph. Oid. K. (= Sophokles, Oedipus Coloneus)

Kullanılan Çeviri: Sophokles, Oidipus Kolonos'ta. Çev.: N. Ataç. İstanbul 1941.

Plat. leg.

(= Platon, leges, [vó $u$ ol])

Kullanılan Çeviri: Platon, Yasalar. Çev.: C. Şentuna - S. Babür. İstanbul 1998.

Plat. Phaidr.

(= Platon, Phaedrus)

Kullanılan Metin ve Çeviri: Plato, Euthyphro, Apology, Crito, Phaedo, Phaedrus. Trans.: H. N. Fowler, vol. I. London - New York 1913 (The Loeb Classical Library).

Thuk.

(= Thukydides)

Kullanılan Metin ve Çeviriler: Thucydides, History of the Peloponnesian War. Trans.: C. F. Smith, vol. I-III. Cambridge - Massachusetts $2003^{11}$ (The Loeb Classical Library).

Peloponnes Savaşı. Çev.: T. Gökçol. İstanbul 1976.

\section{Modern Literatür}

Bruid-Zaidman - Schmitt-Pantel 1999

L. B. Bruid-Zaidman - P. Schmitt-Pantel, Religion in the Ancient Greek City. Cambridge 1999.

Brulé 2012

P. Brulé, Comment Percevoir le Sanctuaire Grec. Paris 2012.

Burkert 1996

W. Burkert, "Greek Temple-Builders: Who, Where and Why?". Ed. R.

Coldstream 1985 Hagg, The Role of the Religion in Early Greek Polis. Stocholm (1996) 21-29.

Eren 2015

J. N. Coldstream, "Greek Temples: Why and Where?". Eds. P. E. Easterling

- J. V. Muir, Greek Religion and Society. Cambridge (1985) 67-97.

K. Eren, "Ionian Sanctuaries and the Mediterranean World in the SeventhCentury B.C.". Eds. P. M. Militello - H. Öniz, Proceedings of the $15^{\text {th }}$ Symposium on Mediterranean Archaeology, Held at the University of Catania 3-5 March 2011, Vol. 1. Oxford (2015) 321-327.

Geertz 1993

C. Geertz, The Interpretation of Cultures. London 1993.

Guettel-Cole 2004

S. Guettel-Cole, Landscapes, Gender and Ritual Space. The Ancient Greek Experience. Berkeley 2004.

Horden - Purcell 2000

Jost 1992

P. Horden - N. Purcell, The Corrupting Sea. Oxford 2000.

Malkin 1987a

M. Jost, Aspects de la Vie Religieuse en Grèce. Paris 1992.

I. Malkin, Religion and Colonization in Ancient Greece. Leiden 1987.

Malkin 1987b

I. Malkin, "La Place des Dieux dans la cité des Hommes". RHR 204 (1987) 331-352.

Malkin 1996

I. Malkin, "Territorial Domination and the Greek Sanctuary". Ed. P. 
Martin 1987

Mazarakis-Ainian 1988

Meigs - Lewis 1969

Morris 1987

Nilsson 1969

Osborne 1987

Polignac 1984

Polignac 1995

Polignac 2006

Rudhardt 2001

Scully 1963

Simon 1997

Snodgrass 2000

Sourvinou-Inwood 1993
Hellström, Religion and Power in the Ancient Greek World. Upssala (1996) 75-81.

R. Martin, "L'espace Civique, Religieux et Profane dans les Cités Grecques de l'archaïsme à l'époque Hellénistique". Ed. R. Martin, Architecture et Urbanisme. Roma (1987) 549-579.

A. J. Mazarakis-Ainian, "Early Greek Temples: Their Origin and Function". Eds. R. Hagg, N. Marinatos - G. Nordquist, Early Greek Cult Practise. Stocholm (1988) 105-119.

R. Meiggs - D. M. Lewis, A Selection of Greek Historical Inscriptions to the End of the Fifth Century B.C. Oxford 1969.

I. Morris, Burial and Ancient Society: The Rise of the Greek City-State. Cambridge 1987.

M. P. Nilsson, Greek Piety. Trans.: H. J. Rose. New York 1969.

R. Osborne, Classical Landscape with Figures. London 1987.

F. de Polignac, La Naissance de la Cité Grecque. Paris 1984.

F. de Polignac, La Naissance de la Cité Grecque. Paris 1995.

F. de Polignac, "Analyse de l'Espace et Urbanisations en Grece Archaique: Quelques Pistes de Recherche Récents". REA 108 (2006) 203-224.

J. Rudhardt, "La Perception Grecque du Territoire Sacré". Ed. Ecole Française de Rome, Image et Religion. Méthodes et Problématiques pour I'antiquité Gréco-Romaine. MEFRA113. Roma (2001) 175-188.

V. Scully, The Earth, the Temple, and the Gods: Greek Sacred Architecture. London - New Haven 1963.

C. G. Simon, "The Archaeology of Cult in Geometric Greece. Ionian Temples, Altars and Dedications". Ed. S. Langdon, New Light on a Dark Age. Columbia (1997) 125-143.

A. M. Snodgrass, "Arkeoloji ve Yunan Kentinin Çalışılması". Eds. J. Rich - A. Wallace-Hadrill, Antik Dünyada Kırsal ve Kent. Çev.: L. Özgenel. İstanbul (2000) 1-24.

C. Sourvinou-Inwood, "Early Sanctuaries, the Eight Century and Ritual Space: Fragments of a Discourse". Eds. N. Marinatos - R. Hagg, Greek Sanctuaries. New Approaches. London - New York (1993) 1-17. 